\title{
The Test-Ban Negotiations: Implications for the Future
}

\author{
By Harold Karan Jacobson
}

\begin{abstract}
The record of the nuclear test-ban negotiations can well be read for its implications both for the procedure of negotiating and the substance of arms-control agreements. The history of the negotiations covers five years and includes an unpoliced moratorium on testing nuclear weapons which lasted nearly three years. Starting with the collapse of the Paris summit meeting in 1960, the negotiations took a radical turn for the worse, and, had it not been for the Cuban crisis and heightened Sino-Soviet tensions, they might well have been fruitless. The level of the United States technical preparation was not adequate to the task at hand, nor were crucial political decisions taken prior to 1961. The impunity with which the Soviet Union could abrogate the moratorium in 1961 demonstrates the danger of dropping one's guard. The experience of the negotiations suggests that areas where there is relative parity perhaps offer the most promise for arms-control agreements and that more progress might be made if greater emphasis were placed on national control or what has come to be called adversary or reciprocal inspection techniques.
\end{abstract}

Harold Karan Jacobson, Ph.D., Ann Arbor, Michigan, is Associate Professor of Political Science, Research Associate in the Law School, and Associate Research Political Scientist in the Center for Research on Confict Resolution at the University of Michigan. He is the editor of America's Foreign Policy (1960) and author of The USSR and the UN's Economic and Social Activities (1963) and has contributed to many publications in international relations. $H e$ is engaged in preparing with Professor Eric Stein of the University of Michigan Law School a detailed analysis of the nuclear testban negotiations entitled Diplomats, Scientists and Politicians. This work is being done under the auspices of the Law School's Atomic Energy Research Project which is supported by funds from the Ford Foundation and the University of Michigan's Phoenix Project. 
F the Treaty Banning Nuclear 1 Weapon Tests in the Atmosphere, in Outer Space, and Under Water, signed at Moscow on August 5, 1963, is to be the first step toward a more peaceful world, the record of the negotiations which led to the treaty can well be studied for its implications for the next steps. That the negotiations yielded the first major formal arms-control agreement between East and West is cause enough for examining them with care. Of all the desultory talks on related topics since the Second World War, what was it that contributed to the unprecedented success of these? What is there to be emulated, and what to be corrected? The record is all the more pertinent since the negotiations involved attempting to create controls for one aspect of the highly complex and rapidly changing technology of the nuclear-missile arms race. In view of the enormous destructive capacities of modern weapons, controlling this race is an essential ingredient in almost all blueprints for a less frightful system of international politics. The record of the nuclear test-ban negotiations contains implications both for the process of attempting to achieve agreements in this area and for their substance.

\section{Overview of the Negotiations}

Since the negotiations were protracted and involved, it may be useful to sketch their course in broad outline before attempting to draw inferences. Although the question of prohibiting or restricting the testing of nuclear weapons had been mooted almost since the dropping of the first bombs on Hiroshima and Nagasaki in August 1945, it did not become a matter of serious political discussion until after the United States detonated a fifteen-megaton thermonuclear device in the Bikini Atoll on March 1, 1954. The injuries to several Marshallese and to some
Japanese fishermen who happened to be in the path of the fallout dramatized one aspect of the danger of continued testing. The more sophisticated were more alarmed by their realization that the techniques involved in this detonation made nuclear weapons much cheaper per megaton of yield and also implied that the possibilities of increasing their destructive capacities were almost limitless. Pressures against the continued testing of nuclear weapons increased sharply as a consequence of this test and the great powers seriously discussed the issue in 1957 during the London meetings of the United Nations disarmament subcommittee.

Actual negotiations did not begin, however, until the following year. They were triggered by the Soviet decision unilaterally to cease testing nuclear weapons and not to resume unless others engaged in testing, which was announced on March 31, 1958, immediately after the completion of the Soviet Union's most extensive test series and shortly before the start of an elaborate American series. The United States response was to request a meeting of technical experts from East and West to examine the question of whether or not a test ban could be adequately monitored. Meanwhile, the planned American test series would go on as scheduled.

\section{The Conference of Experts}

The so-called Geneva Conference of Experts met from July 1 to August 21, 1958 and, after examining the various techniques of detection and identification, concluded that it was "technically feasible to set up, with certain capabilities and limitations, a workable and effective control system for the cessation of nuclear weapons tests." 1 Their re-

1 U. S., Department of State, Documents on Disarmament, 1945-1959 (Publication 7008; Washington, D. C.: Government Printing 
port outlined a control system involving from 160 to 170 land-based control posts and about ten ships, which they estimated would have a "good probability" of detecting and identifying nuclear explosions of yields down to one kiloton in the atmosphere and in the open oceans and also a "good probability" of recording seismic signals from deep underground nuclear explosions equivalent to one kiloton. In the latter case, it was assumed that there would be some difficulty in distinguishing the signals generated by explosions from those generated by earthquakes and that this difficulty would increase significantly as one moved down from five kilotons to one kiloton. It was also known that the only method of establishing positive proof that an underground nuclear explosion had occurred would be through the collection of radioactive debris at the site. For both reasons, some on-site inspections were held to be necessary. Although the Conference of Experts discussed in general terms the problems involved in the detection of nuclear explosions at high altitudes and in outer space, it did not suggest any control apparatus for this environment.

\section{The Geneva Conference}

On the basis of the experts' conclusions, President Dwight D. Eisenhower proposed that the nuclear powers commence negotiations on a test-ban agreement and offered to withhold testing for a period of one year from the beginning of the negotiations. Thus began a moratorium which would last almost three years and the negotiations which would ultimately result in the Moscow Treaty.

The course of the negotiations was

Office, 1960), Vol. 2, p. 1091. For the Communique and the Report of the Conference of Experts, see Ibid., pp. 1090-1111. jagged rather than smooth, though, from surface appearances, they, and American policy within them, followed a logical and coherent pattern. Shortly after the Geneva Conference on the Discontinuance of Nuclear Weapon Tests opened on October 31, 1958, American scientists evaluating the results of the United States 1958 test series concluded that there were serious deficiencies in the control system outlined in the report of the Conference of Experts. In August and early September, the United States had fired -for the first time-several shots at high altitudes, one at height of nearly twenty-seven miles, another at nearly fifty miles, and three at approximately three hundred miles. These tests made obvious the need to add apparatus to detect nuclear explosions at high altitudes and in outer space to the control system proposed by the Conference of Experts.

The analysis of the Hardtack II series of underground explosions conducted in Nevada in September and October created an even more serious problem. The scientists concluded that the seismic magnitude of the one previous underground explosion - the September 1957 Rainier shot-which had formed the principal basis for the calculations of the Conference of Experts, had been estimated incorrectly, that it probably was somewhat smaller than had been thought. This meant that many more earthquakes would generate signals equivalent to those of any given yield underground nuclear explosion than had been assumed and that, consequently, the problem of discrimination between earthquakes and clandestine explosions would be greatly increased. More importantly, the scientists discovered that the background noise normally recorded by seismographs might well obscure the direction of the first motion of a signal generated by an underground 
event, which hitherto had been assumed to be the most important criteria for discriminating between underground explosions and earthquakes. The net result was that the scientists now thought that the threshold below which it was unlikely that the control system would be able to detect underground nuclear explosions was nineteen rather than five kilotons. At roughly the same time, Albert Latter, a physicist employed by the Rand Corporation, doing paper and pencil analysis, discovered that, by detonating a nuclear explosion in a large underground cavity of an appropriate size, it might be possible to muffe its signal by a factor of three hundred. This made the situation considerably more bleak.

The United States response to these developments as it evolved in early 1959 was to launch a research program to see if improved methods could not be found for detecting nuclear explosions and to request further technical talks. At first the Soviet Union refused this request, asserting that the report of the Conference of Experts was, and had to be taken as, the basis for the negotiations. Eventually, in May 1959, the Soviet Union agreed that there should be a brief technical discussion of the problems of detecting nuclear explosions at high altitudes and in outer space. Technical Working Group I, as it was called, met in June and July 1959. During these talks, the Soviet scientists accepted all but one of the control devices suggested by their American counterparts. They refused to accept backscatter radar, on the ground that it could also be used to detect rocket launchings. The Group recommended various measures which could be incorporated in the control system recommended by the Conference of Experts to extend its capabilities to high altitudes and outer space.

The problem of the capability of the system to detect underground nuclear explosions remained, however, and the United States continued to press for technical talks to discuss this. Finally, in early November 1959, the Soviet Union acquiesced, and Technical Working Group II met from November 25 to December 18,1959 . Unlike the preceding meetings of scientists, this session ended in sharp disagreement. The Soviet scientists contested the American evaluation of the Hardtack II data and refused to consider Albert Latter's decoupling theory. Thus, the capability of the control system recommended by the Conference of Experts remained in dispute.

In February 1960 the United States proposed a phased treaty, which would initially outlaw nuclear testing in environments where American scientists felt adequate control could be established and which could be extended as warranted by improvements in control capabilities. The United States had suggested the possibility of a partial ban as early as April 1959, but the Soviet Union had rejected this almost out of hand. In addition, the United States indicated its willingness to enter into a joint research program with the United Kingdom and the Soviet Union to improve control capabilities. After some sparring, the Soviet Union accepted these suggestions on the condition that there be a moratorium on testing in the environments not covered by the initial phase. Agreement seemed to be in sight, and a fourth meeting of scientists from East and West was scheduled to plan a research program. The Seismic Research Program Advisory Group met in May 1960, simultaneously with the planned meeting of heads of state in Paris. At first, the talks proceeded smoothly, and the Soviet scientists seemed to agree that the problem of detecting underground nuclear explosions was more difficult than had originally 
been thought. However, it is an open question whether or not the talks would have produced an agreement had it not been for the denouement in Paris. It was obvious that there were deep differences between the American and Soviet scientists on what to do about low-yield nuclear explosions and the decoupling theory. The Soviet scientists seemed to imply that these problems were beyond solution, at least in politically acceptable terms, and therefore ought not to be examined.

As it was, however, these differences became almost irrelevant. With the collapse of the Paris Summit Meeting, the test-ban negotiations took a radical turn for the worse. From that point on, despite the fact that the Geneva Conference continued in session until January 29, 1962 and the negotiations were carried on after that in other forums, virtually no progress was made until December 1962. Several significant concessions offered by the West after the Kennedy Administration assumed office met only Soviet rebuffs.

\section{The end of the moratorium}

The most notable event was the Soviet Union's unilateral abrogation of the moratorium on nuclear testing on September 1, 1961, despite the pledge given several times by Nikita $S$. Khrushchev and other Soviet leaders, among other places before the General Assembly of the United Nations, that the Soviet Union would not resume testing unless the West did. Earlier in 1961 the Soviet Union had rejected United States suggestions for reciprocal inspection of American and Soviet test sites to ensure that neither side was preparing to test nuclear weapons. The Soviet tests, which clearly were the result of extensive preparations, yielded significant results, and the United States and the United Kingdom felt compelled to conduct tests of their own.

Among other things, these tests provided much more evidence on the problem of detecting underground nuclear explosions, and, on the basis of this and further research which had been conducted in the interim, American scientists concluded that this task was even easier than had been thought during the period of the Conference of Experts, thus reversing their previous pessimistic reappraisal. ${ }^{2}$

\section{The Moscow Treaty}

It is impossible to know what would have happened had not the Cuban crisis occurred in the fall of 1962 . There is some evidence to suggest that both the United States and the Soviet Union felt that only marginal gains could be made in areas of weapons development in which they were interested through further atmospheric testing. Thus, even without a test ban, there might have been a sharp decline in testing in that environment. However, the threat of nuclear war implicit in the Cuban crisis seemed to compel both sides to seek a détente. In late 1962 and early 1963 the question of a comprehensive test ban was again seriously explored, but the Soviet Union was unwilling to accept even the greatly simplified international control mechanisms that the United States proposed. The next and final move, the acceptance in the summer of 1963 of a partial test ban policed by national detection systems, came in the context of a serious deterioration of Sino-Soviet relations.

\footnotetext{
${ }^{2}$ See Director of the Arms Control and Disarmament Agency William C. Foster's testimony before the Senate Subcommittee on Disarmament on July 25, 1962: U. S., Congress, Senate, Committee on Foreign Relations, Subcommittee on Disarmament, Renewed Geneva Negotiations: Hearings (Washington, D. C.: Government Printing Office, 1963), pp. 10-11.
} 


\section{Weaknesses in American Policy}

Viewed in one light, the record can be read as a tribute to American patience and as a triumph for the American concept that arms-control agreements ought only to cover those aspects that can adequately be controlled. In a different light, the record reveals certain basic weaknesses in American policy.

\section{Inadequate technical preparation}

Throughout the negotiations, the level of the United States technical preparation left much to be desired. During the Conference of Experts, the United States based its calculations for elaborating control measures over underground nuclear explosions on one experiment. Subsequent experience proved that this base was too narrow. Several times American scientists discussed and agreed to control devices which did not exist and the real operational capacities of which therefore could not fully be known. An operating prototype of the control station recommended by the Conference of Experts in 1958 did not exist until October 1960. The satellites recommended by Technical Working Group I for the detection of nuclear explosions in outer space were not put into orbit until the fall of 1963 , and an entire system would not be operational for another three years. Twice during the negotiations, the United States attempted to settle technical issues despite the foreknowledge that relevant experiments would be conducted during the technical discussions or after their conclusion. This occurred, as will be recalled, in the case of the Conference of Experts. It also occurred with respect to Technical Working Group II. The first major experiment in Operation Cowboy, a series of chemical explosions designed to test Albert Latter's decoupling theory, was conducted on December 17, 1959, the day before the Working Group recessed. The tests in this series would continue until mid-March 1960.

This is not to argue that the level of American technical preparation was inferior to that of the Soviet Union, for the record certainly does not indicate this. On the contrary, the United States scientists provided by far the largest proportion of the technical data. Given the asymmetrical interest in control - which, regardless of whether or not it is desirable, will probably continue as long as Western societies maintain a higher degree of openness than Communist regimes - the situation requires that the West be better prepared technically than the East. Nor is it to attempt to set absolute and ideal standards by which to judge the American performance. It is merely to state that the United States level of technical preparation was not adequate to the seriousness of the task. Admittedly, it is impossible always to foresee or control the pace of negotiations, but in 1958 a test ban was an issue of long standing, and the United States was unprepared despite its salience.

In part, technical preparation is a function of administrative and financial support. The United States position in 1958, among other things, reflected the relatively low priority accorded to arms control and disarmament matters within the government then. Presumably the situation has at least been improved with the establishment of the Arms Control and Disarmament Agency. Clearly, more human and physical resources are now devoted to tasks in this area. Whether or not sufficient resources are allocated to these matters, though, is an unanswered question. It is perhaps significant that the Vela Project of research concerning the detection of nuclear explosions continues to be housed within the Depart- 
ment of Defense, among other reasons because it would overwhelm the Arms Control and Disarmament Agency. Its annual budget is several times that of the Agency.

Technical preparation is also a function of the linkage between political intelligence and technical research. Forthcoming technical issues have to be defined far enough in advance so that scientists have ample time to probe their complexities. Again, the establishment of the Arms Control and Disarmament Agency should help to create and maintain this linkage. Moreover, the Office of the Special Assistant to the President for Science and Technology and the President's Science Advisory Committee-both created as responses to the sputnik crisis of the fall of 1957-are now much more firmly established as parts of the governmental structure than they were in 1958. Representatives of the scientific community now have an unquestioned place in the nation's highest policy councils. Perhaps as much has been done as is possible in terms of institutional arrangements. The questions which remainand which by their nature are presently unanswerable-center on whether sufficient thought is given to future problems.

\section{Lack of political decisions}

A second weakness in the American position revealed in the nuclear test-ban negotiations is that until 1961 the United States was politically unprepared. Crucial decisions were ignored, postponed, or settled ambiguously. The United States called for the Conference of Experts without any clear notion of what function it would serve, other than to delay matters while the 1958 test series could be carried out. The American scientists went to the Conference of Experts without any firm instructions on the minimum require- ments that a control system would have to meet-especially on the matter of the threshold of detectability - to be consistent with United States security interests. Despite the fact that Technical Working Group I accepted all but one of the detection systems proposed by American scientists, a month and a half elapsed before the United States accepted "the report as a correct technical assessment ... . in the light of presently available scientific knowledge." 3 Almost two years passed before the United States submitted a proposal based on the report of the Working Group for the incorporation of detection devices for high altitude and outer space in the control mechanism.

At no time prior to 1961 did the United States table an entire draft treaty. The basic reason for this situation was the deep division within the Eisenhower Administration on the wisdom of attempting to negotiate a testban treaty. It could be argued, however, that the United States would have been better off not to negotiate at all rather than to negotiate on the basis of an uncertain position. As it was, the United States was cast in an unfavorable light, and its emphasis on control-an important part of its posture with respect to arms control and disarmament matters-was blurred. The United States seemed not to know what it wanted and to be unwilling to accept what its scientists proposed. Moreover, depending on one's estimate of Soviet intentions, it might have been possible to achieve an agreement earlier, and one that perhaps would have been more comprehensive and would have included some international control

${ }^{3}$ Geneva Conference for the Discontinuance of Nuclear Weapon Tests, Document GEN/ DNT/PV. 127, p. 4. Hereafter documents of this conference will be cited by their symbol and number only. 
features. Clearly, if progress is to be made, risks will have to be estimated and balanced and decisions taken. Technical preparation can only be meaningful if there is a framework provided by political decisions.

\section{Failure to maintain a deterrent}

Finally, the inability of the United States to respond rapidly to the Soviet Union's abrogation of the moratorium on nuclear testing demonstrates the danger of dropping one's guard. Starting with fiscal year 1960, no funds had been budgeted for testing nuclear weapons, and test sites were maintained on a minimal basis. There was some construction at the Nevada site in connection with proposed detonations in the peaceful-uses program, but, at the Pacific test site, the only objective was to retard and to the extent possible prevent the inevitable deterioration resulting from the climate. In addition, American scientists appear to have been reluctant to plan weapon tests during the period of the moratorium. Because of the openness of the procedures of American government, such as congressional hearings on budgetary requests, the lack of preparation was in large measure a matter of public knowledge. Thus, the Soviet Union knew in the fall of 1961 that it could break the moratorium without fear of immediate retaliation in kind. Obviously, this is a situation that invites difficulty and, in testifying before the Senate Committee on Foreign Relations in support of the Moscow Treaty, administration leaders pledged that it would not be repeated. ${ }^{4}$ Some participants in the negotiations

${ }^{4}$ See, for example, the testimony of Secretary of Defense Robert S. McNamara and Chairman of the Atomic Energy Commission Glen T. Seaborg: U. S., Congress, Senate, Committee on Foreign Relations, Nuclear Test Ban Treaty: Hearings (Washington, D. C.: Government Printing Office, 1963), pp. 107, 208-209. and analysts of them have gone somewhat farther and questioned the wisdom of engaging in a moratorium before an agreement had been completed. Their argument is that doing this eliminated an incentive to reach agreement.

\section{BROADER IMPLICATIONS}

The negotiations also have broader implications. It is sobering to realize that it took five years to achieve such a limited accord and to consider that even this might not have been gained had it not been for the Cuban crisis and heightened Sino-Soviet tensions.

\section{The necessity for balance}

One explanation for the tedious pace of the negotiations is that both United States and Soviet leaders from time to time appear to have had serious doubts about whether or not stopping testing would actually serve their security interests. It is perhaps instructive that the balance with respect to the state of the art concerning nuclear weapons technology in the Soviet Union and the United States appears to have been much more ambiguous and, in over-all terms, probably more even in 1963 at the time of the signature of the Moscow Treaty than it was in 1958 when the negotiations opened. Indeed, common sense suggests that neither side in a technological race will be willing to stop if it feels that it is behind and there is a chance of catching up. Relative parity, therefore, may well be a useful criterion for use in selecting other areas in which to attempt to negotiate arms-control agreements.

\section{Problems relating to control}

The slow progress of the negotiations can also be attributed to matters relating to the substance of the negotiations, especially to the concept of control. The statement that the United States wanted an international control sys- 
tem while the Soviet Union did not is partially true and conveys some of the difficulties. The controversies centered on the details, and the negotiations set in bold relief the Soviet Union's reluctance to allow incursions into its territory and distrust of international organizations that it does not control. At the same time, the United States was clearly unwilling to countenance the establishment of an international control system in which the Soviet Union's consent would be a necessary condition of most actions. The negotiations thus reaffirmed the common understanding that, in these matters, the international position of the two states and their strategic interests are significantly different.

The negotiations also revealed another difficulty related to the problem of control. The issue was that of attempting to create a control mechanism in an area where relatively little was known and the state of knowledge was rapidly changing.

The American approach was to attempt to frame control measures on the basis of knowledge as of that moment, in as legally precise terms as possible. For example, in the technical discussions the American scientists generally insisted that any agreement specify in detail the characteristics of any instruments recommended for inclusion in the control system. Because the understanding of the technical situation changed during the course of the negotiations, this led to certain embarrassments and other difficulties. At one point during Technical Working Group II, Hans Bethe maintained: ${ }^{5}$

We believe that the experts in 1958 knew quite well about instruments, but we believe that we now know even better about them. We do not believe that the experts of the control commission will know any better than we know.

${ }^{5}$ GEN/DNT/TWG. 2/PV. 12, p. 16.
To argue in abutting sentences that knowledge had changed but would not change again posed, at the least, certain logical complications.

The position of the American scientists was not without justification, however. The negotiations themselves contained a record of dispute about the meanings of agreements, and certainly this has been a prominent feature of the pattern of East-West relations since the Second World War. Moreover, fairly early in the negotiations, it was agreed that any basic changes in the proposed international control system would require the consent of the original parties - that is, of the Soviet Union, the United Kingdom, and the United States. Thus, the American scientists felt that they had to include everything that might conceivably be thought of in any agreement.

The difficulty with the American position was that it could not accommodate technological change. The nuclear test-ban negotiations illustrate clearly how much these matters are subject to change, and the failure of Technical Working Group II shows how difficult it would be to obtain agreement on changing a control system. The Soviet Union was obviously not willing to admit that the control system recommended by the Conference of Experts was not as effective as had been thought and thus by implication to agree that additional control features would be necessary for a comprehensive treaty. One wonders, also, if the United States would have been willing to accept less control than provided in the original agreement, if the technical situation improved, as it subsequently did. Given the asymmetrical position of the two sides on matters of control, simply to negotiate an initial agreement is difficult enough.

Significantly, the Moscow Treaty avoids many of these problems by rely- 
ing primarily on national control systems. Indeed, administration officials testifying in support of the Treaty before the Senate Committee on Foreign Relations cited as one of its attractions the fact that most of the elements to ensure control were solely within the sovereign jurisdiction of the United States and that, therefore, improvements could be made readily and as needed. In the past, American policy concerning arms control has stressed the necessity of international control. Perhaps this experience suggests the wisdom of placing greater emphasis on what can be called reciprocal or adversary control. ${ }^{6}$

${ }^{6}$ The case for such a course is developed persuasively in: Fred C. Iklé and Others, Alternative Approaches to the International Organization of Disarmament (R-391-ARPA; Santa Monica: The Rand Corporation, 1962); Lawrence S. Finkelstein, "The Uses of Reciprocal Inspection," pp. 82-98 in Seymour Melman (ed.), Disarmament: Its Politics and Economics (Boston: The American Academy of Arts and Sciences, 1962); and Lawrence
This might simplify the problem of obtaining agreement and also that of accommodating technological change.

\section{CONCLUSIONS}

It is impossible to predict what will follow the Moscow Treaty. Surely, however, the Treaty in itself should be a cause of some optimism. And, while reviewing the record of the negotiations does not clearly indicate the path to be followed in seeking the next steps toward easing tension between East and West, it does suggest ways in which the United States might improve its capacity to search for this path and certain criteria which might be employed in seeking likely routes. Perhaps this, too, should be a cause for optimism, for it implies that the future is at least to some extent susceptible to manipulation.

S. Finkelstein, "Arms Inspection," International Counciliation, No. 540 (November 1962), pp. 5-89. 